\title{
Antagonistic Impedance Control for Pneumatically Actuated Robot Joints
}

\author{
Alexander Tödtheide, Torsten Lilge, and Sami Haddadin ${ }^{1}$
}

\begin{abstract}
This paper presents a novel joint torque-based impedance controller for antagonistically driven flexible joints actuated by pneumatic cylinders and compares it with the current state of the art. The work targets on transferring soft-robotics control concepts from classical motor-gear-torque sensor setups to pneumatic systems, with the goal of achieving similar performance levels in comparison to this well established technology. A detailed flexible joint model is derived that incorporates the pneumatic and mechanical dynamics of the proposed antagonistic design. This model is used for analyzing model-based control approaches, which in turn are based on reduced order dynamics. The tendon-based joint level impedance controller enables the simultaneous adjustment of closed-loop stiffness and damping. The proposed scheme shows good simulation results for both, position tracking and compliance performance, respectively. Experimentally, an angular position tracking of $7 \mathrm{~Hz}$ could be achieved. Also, stable rigid contacts could be established at considerable impact speed.
\end{abstract}

Index Terms-compliance and impedance control, hydraulic/pneumatic actuators, tendon/wire mechanism

\section{INTRODUCTION}

$\mathbf{E}$ NABLING robot-human-coexistence requires careful design and low-level control. In order to incorporate reactions to external forces on control level, force and compliance control was heavily researched [1], [2], [3], [4]. However, the most widely used control approach enabling physical interaction with a robot is probably impedance control and its related schemes, introduced in [5] and extended to flexible joint robots, e.g. in [6]. Based on high-performance joint force/torque control, this approach imposes a desired physical behavior with respect to external wrenches on the robot. This entire research direction is known as the soft-robotics paradigm.

Nowadays, first commercial compliant systems based on high gearing and joint-level torque sensing are available (known as lightweight robots), opening up the road towards solving the high-precision assembly problem, which is e.g. very typical in the automobile industry. Unfortunately, such solutions are still rather complex and costly. In this respect pneumatic actuators have promising properties for low-cost soft robot structures due to their low weight, simple mechanical design, low price, good power-to-weight ratio, and inherent

Manuscript received: August, 31, 2015; Revised October, 25, 2015; Accepted December, 3, 2015.

This paper was recommended for publication by Paolo Rocco upon evaluation of the Associate Editor and Reviewers' comments. This work is part of a project that has received funding from the European Unions Horizon 2020 research and innovation programme under grant agreement No 688857.

${ }^{1}$ All authors are with Institute of Automatic Control. Faculty of Electrical Engineering and Computer Science, Institute of Automatic Control, Leibniz Universität Hannover, Appelstr. 11 D-30167 Hannover, Germany toedtheide, lilge, haddadin \}airt.uni-hannover.de

Digital Object Identifier (DOI): see top of this page. compliance. Furthermore, they do not require gearing which reduces weight, inertia and friction [7], [8].

Most widely researched pneumatic actuators are cylinders and pneumatic muscle actuators (PMA). The following survey focuses on compliant control approaches for these actuator types: In [9] an impedance controlled cylinder with an inner pressure control and an outer impedance control loop was proposed. Experimental results showed e.g. $10 \mathrm{~Hz}, \pm 1 \mathrm{bar}$ pressure tracking and stability in case of contact. A simultaneous force and stiffness tracking controller was introduced in [10] with force and stiffness tracking up to $4 \mathrm{~Hz}, \pm 50 \mathrm{~N}$, as well as position tracking experiments with $2 \mathrm{~Hz}$, using an external position controller. A backstepping sliding-mode control approach was applied in [7], allowing force/stiffness tracking at $14 \mathrm{~Hz}$ with an error in amplitude of about $5 \%$. The potentially unstable behavior of an impedance controlled pneumatic system with low load inertias was investigated in [11].

In [12] PMAs were applied to an antagonistically driven, multi-joint robot exoskeleton using a position-based impedance control approach. An antagonistic PMA-DCmotor-driven joint was proposed in [13], where the DC motor adds the capability of high bandwidth tracking, resulting in an improvement of the torque step response rise time from $0.35 \mathrm{~s}$ to $0.15 \mathrm{~s}$. An outer impedance control loop provides the position behavior. Force/stiffness controllers for PMAs were considered in [14] and [15]. The latter uses a dissipativity based force controller with a numerical and experimental force model providing less than $2.5 \%$ error.

Up to now, control strategies were either applied to linearly moving pneumatic cylinders or to antagonistically driven PMAs. This paper presents a novel joint torque impedance control scheme for pneumatic cylinders in an antagonistic setup, enabling a direct implementation on rotary joints. The setup provides a linear relation between joint angle and piston displacement, supporting the concept of direct backdrivability. Nonlinear kinematics and singularities are avoided and lightweight design is enabled, since actuators are not directly placed at the joint. Antagonism prevents buckling of piston rods and allows a simultaneous adjustment of damping and stiffness. While PMAs suffer from several drawbacks like hysteresis, dead bands, friction, slow dynamics (especially when depressurizing) [16] or small stroke lengths, pneumatic cylinders were chosen due to their fast and accurate responses [8] and because analytical models of pressurized air in a distinct geometry show better accuracy. Low friction components improve system performance and enable haptic sensing of internal pressure sensors, where PMAs require additional load cells. Related to the variable impedance actuators shown in [16], this work provides a compliant actuation concept, which already includes inherent compliant elements by compressibility of air, mitigating impacts and allowing energy 
This is the author's version of an article that has been published in this journal. Changes were made to this version by the publisher prior to publication. The final version of record is available at http://dx.doi.org/10.1109/LRA.2015.2511663

TABLE I

STATE-OF-THE-ART IN COMPLIANT CONTROL OF PNEUMATIC CYLINDERS AND PNEUMATIC MUSCLE ACTUATORS (PMAS)

\begin{tabular}{|c|c|c|c|c|c|c|c|c|c|}
\hline & \multicolumn{4}{|c|}{ Pneumatic cylinders } & \multicolumn{4}{|c|}{ Pneumatic muscle actuators (PMAs) } & \multirow[b]{2}{*}{ our work } \\
\hline & Zhu [9] & Shen [10] & Taheri [7] & Arbab [11] & Noritsugu [12] & Sardellitti [13] & Sardellitti [14] & Ugurlu [15] & \\
\hline Actuators & single cylinder & single cylinder & single cylinder & single cylinder & $\begin{array}{l}\text { antagonistic } \\
\text { PMA }\end{array}$ & $\begin{array}{l}\text { antagonistic } \\
\text { PMA (+ } \\
\text { DC-motor) }\end{array}$ & $\begin{array}{l}\text { antagonistic } \\
\text { PMA }\end{array}$ & $\begin{array}{l}\text { antagonistic } \\
\text { PMA }\end{array}$ & $\begin{array}{l}\text { antagonistic } \\
\text { cylinders }\end{array}$ \\
\hline Valves/unit & $\begin{array}{l}2 \times \\
\text { proportional }\end{array}$ & \begin{tabular}{|l|}
$2 \times$ \\
proportional
\end{tabular} & $\begin{array}{l}2 \times \\
\text { proportional }\end{array}$ & $\begin{array}{l}2 \times \text { switching } \\
\text { solenoid }\end{array}$ & $\begin{array}{l}7 \times \text { digital } \\
\text { switches }\end{array}$ & $\begin{array}{l}2 \times \text { pressure } \\
\text { regulator }\end{array}$ & $\begin{array}{l}2 \times \text { switching } \\
\text { solenoid }\end{array}$ & $\begin{array}{l}2 \times \text { pressure } \\
\text { regulator }\end{array}$ & $\begin{array}{l}2 \times \\
\text { proportional }\end{array}$ \\
\hline \begin{tabular}{|l} 
Pneumatic \\
model
\end{tabular} & $\begin{array}{l}\text { isothermal gas } \\
\text { equation }\end{array}$ & $\begin{array}{l}\text { isothermal gas } \\
\text { equation }\end{array}$ & $\begin{array}{l}\text { isothermal gas } \\
\text { equation }\end{array}$ & $\begin{array}{l}\text { isothermal gas } \\
\text { equation }\end{array}$ & $\begin{array}{l}\text { static pneumatic } \\
\text { model }\end{array}$ & \begin{tabular}{|l|} 
static \\
force/input- \\
signal
\end{tabular} & $\begin{array}{l}\text { static } \\
\text { force/input- } \\
\text { signal with } \\
\text { PT1 }\end{array}$ & \begin{tabular}{|l|} 
numerical \\
approximation
\end{tabular} & $\begin{array}{l}\text { gas equation } \\
\text { with weighted } \\
\text { in/-outflows }\end{array}$ \\
\hline $\begin{array}{l}\text { Mechanical } \\
\text { model }\end{array}$ & $\begin{array}{l}\text { mass-damping } \\
\text { with Coulomb } \\
\text { friction }\end{array}$ & stiffness & stiffness & $\begin{array}{l}\text { mass-spring- } \\
\text { damper }\end{array}$ & $\begin{array}{l}\text { kinematic } \\
\text { 2-DoF }\end{array}$ & \begin{tabular}{|l} 
antagonistic \\
tendon-based \\
visco-elastic \\
joint \\
\end{tabular} & \begin{tabular}{|l|} 
stiffness \\
\end{tabular} & stiffness & \begin{tabular}{|l|} 
antagonistic \\
tendon-based \\
visco-elastic \\
joint \\
\end{tabular} \\
\hline $\begin{array}{l}\text { Actuator inner } \\
\text { cycle }\end{array}$ & $\begin{array}{l}2 \text { sliding-mode } \\
\text { pressure } \\
\text { controllers per } \\
\text { cylinder }\end{array}$ & $\begin{array}{l}1 \text { MIMO } \\
\text { sliding-mode } \\
\text { force and } \\
\text { stiffness } \\
\text { controller per } \\
\text { cylinder } \\
\end{array}$ & $\begin{array}{l}2 \text { backstepping } \\
\text { sliding-mode } \\
\text { pressure } \\
\text { controller per } \\
\text { cylinder }\end{array}$ & $\begin{array}{l}2 \text { sliding mode } \\
\text { pressure } \\
\text { controllers per } \\
\text { cylinder }\end{array}$ & $\begin{array}{l}\text { PI-controller, } \\
\text { including static } \\
\text { characteristic } \\
\text { pressure/force } \\
\text { curve }\end{array}$ & $\begin{array}{l}\text { Macro-Mini- } \\
\text { force } \\
\text { control }\end{array}$ & $\begin{array}{l}\text { sliding mode } \\
\text { force control } \\
\text { (force/stiffness } \\
\text { transformation) }\end{array}$ & $\begin{array}{l}\text { Force control } \\
\text { (force/stiffness } \\
\text { transformation } \\
\text { using numerical } \\
\text { model) }\end{array}$ & $\begin{array}{l}1 \text { sliding mode } \\
\text { force control } \\
\text { per cylinder }\end{array}$ \\
\hline $\begin{array}{l}\text { Actuator outer } \\
\text { cycle }\end{array}$ & $\begin{array}{l}\text { force control } \\
\text { (pressure/force } \\
\text { transformation) }\end{array}$ & & $\begin{array}{l}\text { force and } \\
\text { stiffness control } \\
\text { (pressure/force } \\
\text { stiffness } \\
\text { transformation) }\end{array}$ & & & & & & \\
\hline $\begin{array}{l}\text { Joint outer } \\
\text { cycle }\end{array}$ & $\begin{array}{l}\text { prismatic joint } \\
\text { impedance } \\
\text { control }\end{array}$ & - & $\begin{array}{l}\text { impedance } \\
\text { control }\end{array}$ & $\begin{array}{l}\text { prismatic joint } \\
\text { impedance } \\
\text { control }\end{array}$ & \begin{tabular}{|l|} 
position-based \\
joint impedance \\
controller
\end{tabular} & \begin{tabular}{|l|} 
antagonistic \\
joint \\
torque-based \\
impedance \\
control \\
\end{tabular} & $\begin{array}{l}\text { force/stiffness } \\
\text { control }\end{array}$ & $\begin{array}{l}\text { force/stiffness } \\
\text { control }\end{array}$ & \begin{tabular}{|l|} 
antagonistic \\
joint \\
torque-based \\
impedance \\
control \\
\end{tabular} \\
\hline $\begin{array}{l}\text { Position } \\
\text { Measurement }\end{array}$ & potentiometer & potentiometer & \begin{tabular}{|l|} 
magnetic \\
position sensor
\end{tabular} & potentiometer & $\begin{array}{l}\text { rotary encoder } \\
\text { (joint side) }\end{array}$ & $\begin{array}{l}\begin{array}{l}\text { rotary encoder } \\
\text { (joint side) }\end{array} \\
\end{array}$ & 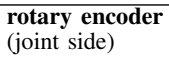 & \begin{tabular}{|l} 
rotary encoder \\
(joint side)
\end{tabular} & \begin{tabular}{|l|} 
magnetic \\
position sensor
\end{tabular} \\
\hline $\begin{array}{l}\text { Force } \\
\text { measurement }\end{array}$ & pressure sensors & pressure sensors & \begin{tabular}{|l|} 
pressure sensors \\
\end{tabular} & $\begin{array}{l}\text { pressure } \\
\text { sensors, load } \\
\text { cell }\end{array}$ & pressure sensors & $\begin{array}{l}\text { pressure sensor, } \\
\text { load cell }\end{array}$ & $\begin{array}{l}\text { pressure sensor, } \\
\text { load cell }\end{array}$ & $\begin{array}{l}\text { pressure sensor, } \\
\text { load cell }\end{array}$ & $\begin{array}{l}\text { pressure } \\
\text { sensor }\end{array}$ \\
\hline $\begin{array}{l}\text { Acutator } \\
\text { dimensions }\end{array}$ & $\begin{array}{l}\text { stroke: } 15 \mathrm{~cm}, \\
\varnothing: 2 \mathrm{~cm}\end{array}$ & $\begin{array}{l}\text { stroke: } 10 \mathrm{~cm}, \\
\varnothing: 2.7 \mathrm{~cm} \\
\varnothing:\end{array}$ & $\begin{array}{l}\text { stroke: } 7.5 \mathrm{~cm}, \\
\varnothing: 0.9 \mathrm{~cm}\end{array}$ & $\begin{array}{l}\text { stroke: } 140 \mathrm{~cm} \text {, } \\
\varnothing: 2.5 \mathrm{~cm}\end{array}$ & $\begin{array}{l}\text { length: } \approx 30 \mathrm{~cm}, \\
\varnothing: \approx 5 \mathrm{~cm}\end{array}$ & $\begin{array}{l}\text { length: } 21 \mathrm{~cm} \text {, } \\
\varnothing: \approx 5 \mathrm{~cm}\end{array}$ & $\begin{array}{l}\text { length: } 17 \mathrm{~cm} \text {, } \\
\varnothing: 3 \mathrm{~cm}\end{array}$ & $\begin{array}{l}\text { length: } \approx 30 \mathrm{~cm}, \\
\varnothing: \approx 5 \mathrm{~cm}\end{array}$ & $\begin{array}{l}\text { stroke: } 7.5 \mathrm{~cm} \text {, } \\
\varnothing: 0.9 \mathrm{~cm}\end{array}$ \\
\hline $\begin{array}{l}\text { Best exp. } \\
\text { actuator level }\end{array}$ & $\begin{array}{l}10 \mathrm{~Hz} \\
@ \pm 1 \text { bar }\end{array}$ & $\begin{array}{l}4 \mathrm{~Hz} @ \\
\pm 50 \mathrm{~N}\end{array}$ & $\begin{array}{l}14 \mathrm{~Hz} @ \\
\pm 15 \mathrm{~N}\end{array}$ & $\begin{array}{l}1 \mathrm{~Hz} @ \\
\pm 2 \text { bar }\end{array}$ & N.A. & $\begin{array}{l}0.1 \mathrm{Nm} \text { step, } \\
\tau=0.2 \mathrm{~s}\end{array}$ & $\begin{array}{l}1.5 \mathrm{~Hz} @ \\
\pm 2 \mathrm{Nm}\end{array}$ & $\begin{array}{l}2.2 \mathrm{~Hz} @ \\
\pm 15 \mathrm{Nm}\end{array}$ & $\begin{array}{l}10 \mathrm{~Hz} @ \\
\pm 12.5 \mathrm{~N}\end{array}$ \\
\hline $\begin{array}{l}\text { Best exp. joint } \\
\text { level }\end{array}$ & $\begin{array}{l}1.5 \mathrm{~Hz} \\
@ \pm 50 \mathrm{~mm}\end{array}$ & $\begin{array}{l}2 \mathrm{~Hz} \\
@ \pm 22 \mathrm{~mm}\end{array}$ & N.A. & N.A. & N.A. & $\begin{array}{l}0.065 \mathrm{rad} \\
\text { step, } \tau=0.8 \mathrm{~s}\end{array}$ & N.A. & \begin{tabular}{|l|} 
N.A. \\
\end{tabular} & $\begin{array}{l}7 \mathrm{~Hz} @ \\
\pm 1 \mathrm{rad} \triangleq \\
\pm 18 \mathrm{~mm}, \\
0.8 \mathrm{rad} \mathrm{step}, \\
\tau=0.1 \mathrm{~s}\end{array}$ \\
\hline
\end{tabular}

storage. Consequently, the current work can be seen as an intermediate step towards a real variable impedance actuator using the inherent capabilities of pneumatics beyond force and impedance control. Table I systematically compares the different pneumatic technologies mentioned above with our approach, revealing less hardware components in contrast to PMAs, a good actuator level torque tracking (especially in comparison to PMAs) and the fastest joint angle tracking. The bold characters in Tab. I point out relevant differences or similarities. The overall contributions of the paper are

1) a systematic comparison of approaches for force or impedance controlled pneumatic systems (see Tab. I),

2) the design, flexible modeling, and identification of a novel joint torque-controlled antagonistic pneumatically actuated robot joint,

3) simulative performance comparisons between four controllers from literature (see Fig. 4), and between two pneumatic tendon force controllers in an antagonistic setup (see Fig. 5 and 6), as well as

4) the simulative and experimental validation of cascaded control for pneumatic cylinder force, joint torque, and joint impedance control in an antagonistic setup.

In order to develop the proposed antagonistic pneumatics based impedance controlled actuation concept, a detailed pneumatic/mechanical model has to be derived, which captures all essential physical effects. Since high-performance jointlevel impedance control relies on an inner force loop, which constitutes a joint torque control level in an antagonistic symmetric setup, two promising force controllers from literature (see [17]) were chosen and investigated. The joint level is then controlled via a tendon-based impedance control approach. Based on simulation analysis incorporating relevant real world effects, the more promising force controller was selected for subsequent experimental implementation and evaluation of the overall control approach.

The paper is organized as follows. Section II describes the modeling of the linear pneumatic actuator and the flexible mechanical joint. The inner force control is outlined in Sec. III. Section IV deals with the outer loop impedance control. Simulation results of the antagonistically controlled pneumatic joint are presented in Sec. V. The parameters and results of the experimental validation are presented and discussed in Section VI. Finally, Section VII concludes the paper.

\section{SYSTEM MODELING}

In the first part of this section the considered pneumatic model is derived. In the second part, the pneumatic actuator is embedded into a full flexible joint model.

\section{A. Pneumatic actuator}

The pneumatic modeling is done based on [8]. The motion of the piston can be described by (see Fig. 1)

$$
\ddot{x}_{\mathrm{p}} M_{\mathrm{p}}=P_{1} A_{1}-P_{2} A_{2}-P_{\mathrm{atm}} A_{\mathrm{r}}-F_{\mathrm{f}}-F_{\text {ext }} .
$$




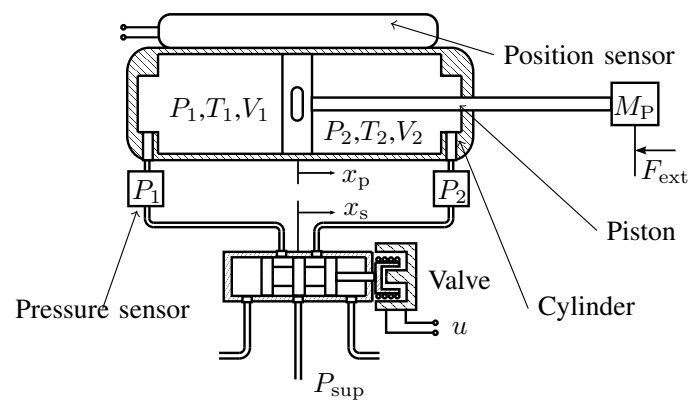

Fig. 1. Mechanical model of a pneumatic cylinder system

$M_{\mathrm{p}}$ and $x_{\mathrm{p}}$ denote piston mass and position. $P_{1}$ and $P_{2}$ are the pressures of the single chambers, applying a force to the surface $A_{1}$ and $A_{2}$, respectively. The atmospheric pressure $P_{\text {atm }}$ affects the area $A_{\mathrm{r}}$, which is the cross sectional area of the rod leaving the cylinder. Friction and external forces are denoted by $F_{\mathrm{f}}$ and $F_{\text {ext }}$. A constant supply pressure $P_{\text {sup }}$ is assumed. Pressures $P_{1}$ and $P_{2}$ are obtained by the following pressure dynamic state equation

$$
\frac{d P}{d t}=\frac{R T_{\text {atm }}}{V}\left(\alpha_{\text {in }} \dot{m}_{\text {in }}-\alpha_{\text {out }} \dot{m}_{\text {out }}\right)-\alpha \frac{P}{V} \dot{V},
$$

which was proposed in [8]. This approach obtains an improved pressure evolution in contrast to an isothermal assumption by introducing the constants $\alpha, \alpha_{\text {in }}$, and $\alpha_{\text {out }} . \alpha_{\text {in }}$ denotes effects, which are related to a charging process. According to [17], this factor should be chosen close to $\gamma=\frac{c_{\mathrm{p}}}{c_{\mathrm{v}}}$, being the ratio of heat capacities of air at constant pressure and volume. The parameter $\alpha_{\text {out }}$ denotes effects which are caused by a discharging process. This factor should be chosen close to 1 . The factor $\alpha$ weights the pressure changes due to piston movement and according to [18] should be chosen as 1.2. The parameter $R$ is the specific gas constant of air. $T_{\mathrm{atm}}$ is the atmospheric temperature. In- and outflowing masses are described by $\dot{m}_{\text {in }}$ and $\dot{m}_{\text {out }}$. The volumes $V=V_{0 i}+\left(L / 2 \pm A_{i} x_{\mathrm{p}}\right)$ of chambers 1 and 2 depend on the piston position $x_{\mathrm{p}}$. The volumes $V_{01}$ and $V_{02}$ represent dead volumes at the maximum and minimum piston position.

Mass flows $\dot{m}$ are controlled by the valves and can be modeled by the nozzle equation

$$
\dot{m}=c_{\mathrm{f}} A_{\mathrm{v}} P_{\mathrm{u}} \Psi\left(P_{\mathrm{d}} / P_{\mathrm{u}}\right),
$$

considering a pressure potential between an upstream pressure $P_{\mathrm{u}}$ and a downstream pressure $P_{\mathrm{d}}$, separated by an orifice of area $A_{\mathrm{v}}$. The parameter $c_{\mathrm{f}}$ is a discharge coefficient. The flow function $\Psi$ in (3) takes the form

$$
\Psi= \begin{cases}\sqrt{\frac{2 \gamma}{R T_{\mathrm{u}}(\gamma-1)}\left[\left(\frac{P_{\mathrm{d}}}{P_{\mathrm{u}}}\right)^{\frac{2}{\gamma}}-\left(\frac{P_{\mathrm{d}}}{P_{\mathrm{u}}}\right)^{\frac{\gamma+1}{\gamma}}\right]} & \frac{P_{\mathrm{d}}}{P_{\mathrm{u}}} \geq P_{\text {krit }} \\ \sqrt{\frac{\gamma}{R T_{\mathrm{u}}} \frac{2}{\gamma+1} \frac{\gamma+1}{\gamma-1}} & \frac{P_{\mathrm{d}}}{P_{\mathrm{u}}}<P_{\text {krit }}\end{cases}
$$

where $P_{\text {krit }}=\left(\frac{2}{\gamma+1}\right)^{\frac{\gamma}{\gamma-1}}$ for the heat capacity ratio $\gamma \in \mathbb{R}^{+}$ with $\gamma=1.4$. The allocation between $P_{\mathrm{u}}$ and $P_{\mathrm{d}}$ and $P_{1}, P_{2}$, $P_{\text {atm }}$ is implemented by case analysis. The mass flow $\dot{m}$ is controlled by proportional valves, where the spool position $x_{\mathrm{s}}$ affects the area

$$
A_{\mathrm{v}}=A\left(x_{\mathrm{s}}\right)
$$

being a specific geometric relationship of the valve. The spool is actuated by a coil, generating a force $F_{\mathrm{c}}=K_{\mathrm{c}} i_{\mathrm{c}}$ where $i_{\mathrm{c}}$

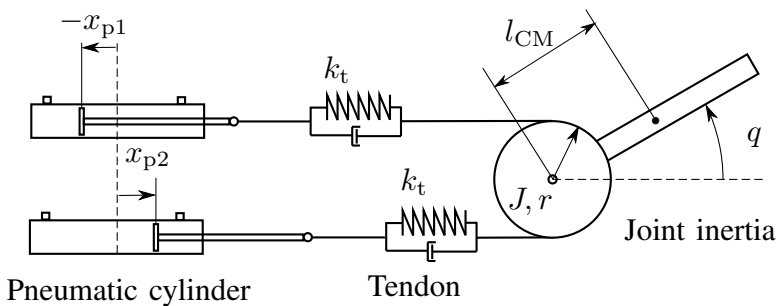

Fig. 2. Mechanical model of the antagonistic pneumatic robot joint

is a current, $K_{\mathrm{c}}$ a coil constant and $2 k_{\mathrm{s}}$ a resetting spring. Neglecting the spool mass the dynamics of $M_{\mathrm{s}}, x_{\mathrm{s}}$ can be modeled as

$$
\dot{x}_{\mathrm{s}}=-\frac{2 k_{\mathrm{s}}}{d_{\mathrm{s}}} x_{\mathrm{s}}+\frac{K_{\mathrm{c}}}{d_{\mathrm{s}}} i_{\mathrm{c}}=-\frac{1}{\tau} x_{\mathrm{s}}+\frac{K}{\tau} u,
$$

where $d_{\mathrm{S}}$ is a viscous friction constant and $u$ an input voltage. The system is furthermore characterized by its time constant $\tau$ and gain $K$. The state equation of the overall pneumatic system with the state vector $\boldsymbol{x}_{\mathrm{C} i}=\left(P_{1}, P_{2}, x_{\mathrm{s}}, \dot{x}_{\mathrm{p}}, x_{\mathrm{p}}\right)^{T}$ can then be written as

$$
\dot{\boldsymbol{x}}_{C i}=\left(\begin{array}{c}
\frac{R T_{\mathrm{atm}}}{V_{1}}\left(\alpha_{\mathrm{in}} \dot{m}_{\mathrm{in}, 1}-\alpha_{\mathrm{out}} \dot{m}_{\mathrm{out}, 1}\right)-\alpha \frac{P_{1}}{V_{1}} \dot{V}_{1} \\
\frac{R T_{\mathrm{atm}}}{V_{2}}\left(\alpha_{\mathrm{in}} \dot{m}_{\mathrm{in}, 2}-\alpha_{\mathrm{out}} \dot{m}_{\mathrm{out}, 2}\right)-\alpha \frac{P_{2}}{V_{2}} \dot{V}_{2} \\
-\frac{1}{\tau} x_{\mathrm{s}}+\frac{K}{\tau} u \\
\frac{1}{M_{\mathrm{p}}}\left(P_{1} A_{1}-P_{2} A_{2}-P_{\mathrm{atm}} A_{\mathrm{r}}-F_{\mathrm{f}}+F_{\mathrm{ext}}\right) \\
\dot{x}_{\mathrm{p}}
\end{array}\right),
$$

where $\dot{m}_{\text {out }, i}$ and $\dot{m}_{\mathrm{in}, i}$ depend on specific up- and downstream in dependency of $x_{\mathrm{p}}$. The inputs of the system are $u$ and $F_{\text {ext }}$.

\section{B. Robot joint model}

Figure 2 depicts the mechanical model of the pneumatic antagonistically actuated robot joint. The system is modeled as three independently movable elements (two pistons and a joint inertia). The joint inertia is represented by a roller pulley of radius $r$ and inertia $J$, which can perform rotational motions about the joint angle $q$. It is assumed that two tendons 1 and 2 are fixed at an outer radius $r$ and that no coupling between the tendons exists. Each tendon is linked to a linear pneumatic actuator, which can induce negatively defined forces $F_{\mathrm{t} i}$ to the roller pulley. Due to the pretension force $F_{\mathrm{p} i}$, that is handled by the force controller, slacking does not need to be taken into account. Putting together the full flexible joint model leads to

$$
\begin{aligned}
J \ddot{q}-M_{\mathrm{j}} l_{\mathrm{CM}} \cos (q) & =r\left(F_{\mathrm{t} 2}-F_{\mathrm{t} 1}\right)-\tau_{\mathrm{f}}+\tau_{\mathrm{ext}} \\
\dot{\boldsymbol{x}}_{\mathrm{C} 1} & =f_{1}\left(\boldsymbol{x}_{\mathrm{C} 1}, F_{\mathrm{t} 1}, u_{1}\right) \\
\dot{\boldsymbol{x}}_{\mathrm{C} 2} & =f_{2}\left(\boldsymbol{x}_{\mathrm{C} 2}, F_{\mathrm{t} 2}, u_{2}\right) \\
F_{\mathrm{t} 1} & =k_{\mathrm{t}}\left(q r-x_{\mathrm{p} 1}\right)+d_{\mathrm{t}}\left(\dot{q} r-\dot{x}_{\mathrm{p} 1}\right) \\
F_{\mathrm{t} 2} & =k_{\mathrm{t}}\left(q r-x_{\mathrm{p} 2}\right)+d_{\mathrm{t}}\left(\dot{q} r-\dot{x}_{\mathrm{p} 2}\right) .
\end{aligned}
$$

Equation (8) follows from the sum of torques, where $l_{\mathrm{CM}}$ is the position of the center of mass with respect to the mass $M_{\mathrm{j}}$ of the joint link. The pneumatic state equations $f_{1}$ and $f_{2}$ were already introduced in (7). External and friction torques are incorporated via $\tau_{\text {ext }}$ and $\tau_{\mathrm{f}}$. Since the tendon material consists of a fiber material, tendon elasticity with spring and damping constants $k_{\mathrm{t}}$ and $d_{\mathrm{t}}$ may be assumed if required. The flexible joint modeling is not considered in the controller design since the maximum theoretical tendon elongation of our setup is $0.12 \mathrm{~mm}$ for a tendon force of $30 \mathrm{~N}$. The tendon 
parameters are considered to be $E=55000 \ldots 172000 \mathrm{MPa}$, $L_{0}=0.4 \mathrm{~m}, r=0.75 \mathrm{~mm}$ of the dyneema fiber material. However, in the plant simulation, the appropriate elasticities are indeed implemented in order to obtain more realistic controller performance under disturbances.

\section{FORCE CONTROL}

In our work a 1st- and a 2nd-order sliding mode force control approach based on [17] is used. The actual force $F_{\mathrm{a}}$, which is generated by a linear pneumatic actuator, can be obtained from (1) as

$$
F_{\mathrm{a}}=F_{\text {ext }}=P_{1} A_{1}-P_{2} A_{2}-P_{\mathrm{atm}} A_{\mathrm{r}}-\beta_{\mathrm{v}} \dot{x}_{\mathrm{p}}-\beta_{\mathrm{c}},
$$

where $\beta_{\mathrm{v}}$ denotes a viscous and $\beta_{\mathrm{c}}$ a Coulomb friction parameter (assuming $M_{\mathrm{p}} \approx 0$ ). However, practically influences of friction can be neglected due to the use of low friction components, i.e. $\beta_{\mathrm{c}} \approx 0$. The force controllers make use of the reduced order pneumatic model (2). Following [17], a general sliding mode force controller is designed based on the sliding mode

$$
s(t)=\left(\frac{d}{d t}+\lambda\right)^{n-1} \tilde{F}=0,
$$

with $\tilde{F}=F_{\text {a }}-F_{\mathrm{d}}$ and $F_{\mathrm{d}}$ being the desired force. Thus, controlling of $\tilde{F}$ is transformed into a first order stabilization problem in $s$ [17]. The stabilization follows by applying an equivalent control input $u_{\text {eq }}$, which is obtained demanding $\dot{s}=$ 0 . Full expressions for $u_{\mathrm{eq}}$ can be found in [17]. In addition to $u_{\text {eq }}$, a switching term ensures the convergence to the sliding mode if $s \neq 0$ resulting in

$$
u=u_{\mathrm{eq}}-\kappa \operatorname{sat}\left(\frac{s}{\Gamma}\right),
$$

with control constants $\kappa$ and $\Gamma$. These were tuned using numerical optimization (see Sec. V). The saturation function in (15) is defined as

$$
\operatorname{sat}(y)= \begin{cases}-1 & \text { if } y<-1 \\ y & \text { if }|y| \leq 1 \\ +1 & \text { if } y>+1\end{cases}
$$

1) First order: The 1st-order $(n=1)$ sliding mode approach neglects the spool dynamics (6), leading to the linear relation $u=x_{\mathrm{s}} / K$. The sliding surface can then be defined by combining (13), (14) and $\tilde{F}=F_{\mathrm{a}}-F_{\mathrm{d}}$ as

$$
s=\tilde{F}=P_{1} A_{1}-P_{2} A_{2}-P_{\text {atm }} A_{\mathrm{r}}-\beta_{\mathrm{v}} \dot{x}_{\mathrm{p}}-F_{\mathrm{d}} .
$$

Applying $\dot{s}(t)=0$ leads to

$$
\dot{s}=\dot{P}_{1} A_{1}-\dot{P}_{2} A_{2}-\beta_{\mathrm{v}} \ddot{x}_{\mathrm{p}}-\dot{F}_{\mathrm{d}}=0
$$

requiring $\dot{P}_{i}$, which can be obtained from the pressure dynamics (2). The equivalent input $u_{\mathrm{eq}}$ then follows from the inverse function $x_{\mathrm{eq}}\left(A_{\mathrm{eq}}\right)$ of the orifice function (5). When solving (18) for $A_{\text {eq }}$, a case distinction needs to be implemented in order to differentiate between in- and outflow. In our work the orifice function $A\left(x_{\mathrm{s}}\right)$ and its inverse function were modeled by cubic splines based on measurements (see Fig. 8) instead of using a series expansion as implemented in [17].

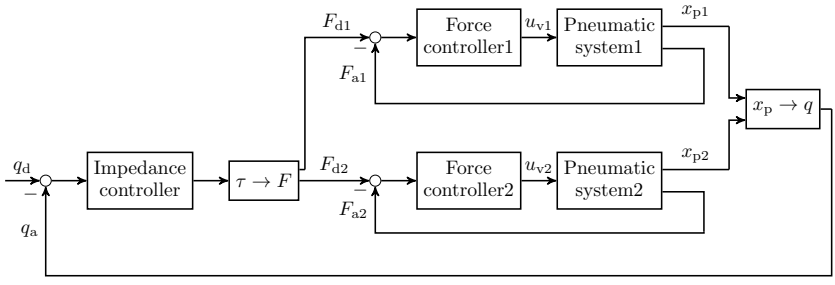

Fig. 3. Signal flow diagram of impedance control for the tendon driven pneumatic system

2) Second order: The 2nd-order sliding mode controller $(n=2)$ considers the spool dynamics of $x_{\mathrm{s}}(6)$. In analogy to (14), the sliding surface is

$$
\begin{aligned}
s= & \lambda\left(P_{1} A_{1}-P_{2} A_{2}-P_{\mathrm{atm}} A_{\mathrm{r}}-F_{\mathrm{d}}\right) \\
& +\dot{P}_{1} A_{1}-\dot{P}_{2} A_{2}-\dot{F}_{\mathrm{d}}-\lambda \beta_{\mathrm{v}} \dot{x}_{\mathrm{p}}-\beta_{\mathrm{v}} \ddot{x}_{\mathrm{p}} .
\end{aligned}
$$

Setting $\dot{s}=0$ leads to

$$
\begin{aligned}
\dot{s}= & \lambda\left(\dot{P}_{1} A_{1}-\dot{P}_{2} A_{2}-\dot{F}_{\mathrm{d}}\right)+\ddot{P}_{1} A_{1}-\ddot{P}_{2} A_{2}-\ddot{F}_{\mathrm{d}} \\
& -\lambda \beta_{\mathrm{v}} \ddot{x}_{\mathrm{p}}-\beta_{\mathrm{v}} \dddot{x}_{\mathrm{p}}=0 .
\end{aligned}
$$

The second order derivatives $\ddot{P}_{i}$ are obtained from (2). This requires time derivatives of (4) and (5). The equivalent voltage $u_{\mathrm{eq}}$ is obtained from (20) for $\dot{x}_{\mathrm{s}}$ and insertion into (6). The spool velocity $x_{\mathrm{s}}$ was determined using an unscented Kalman filter [19] based on the pressure state equation (2) of a single chamber and the spool dynamics (6).

\section{ANTAGONISTIC TENDON BASED IMPEDANCE CONTROL}

\section{A. Antagonistic system}

The overall impedance controller structure for the antagonistic robot joint is shown in Fig. 3. It consists of an impedance controller on joint level and two underlying force controllers on tendon level. The impedance control law, applied to the pneumatically driven joint, is denoted by the impedance control together with an acceleration feed forward term for better tracking accuracy as

$$
\begin{aligned}
\tau_{\mathrm{ff}} & =\left(J+2 r^{2} M_{\mathrm{p}}\right) \ddot{q}_{\mathrm{d}} \\
\tau_{\mathrm{d}} & =k_{\mathrm{imp}}\left(q_{\mathrm{d}}-q\right)+d_{\mathrm{imp}}\left(\dot{q}_{\mathrm{d}}-\dot{q}\right)+\hat{g}(q)+\tau_{\mathrm{ff}} .
\end{aligned}
$$

$k_{\text {imp }}$ denotes the desired stiffness, $\hat{g}(q)$ is the gravity compensation and $\tau_{\mathrm{ff}}$ a feed-forward term compensating for the inertial effects. Please note that in our controller we do not consider inertia shaping. However, in principle this would be possible via an appropriate estimation and feedback of external torques. $d_{\mathrm{imp}}$ is chosen to be

$$
d_{\mathrm{imp}}=2 D \sqrt{k_{\mathrm{imp}}\left(J+2 r^{2} M_{\mathrm{p}}\right)},
$$

using the desired damping ratio $D$. The ideal closed loop behavior is

$$
\left(J+2 r^{2} M_{\mathrm{p}}\right) \ddot{\varphi}+d_{\mathrm{imp}} \dot{\varphi}+k_{\mathrm{imp}} \varphi=\tau_{\mathrm{ext}},
$$

with $\varphi:=q_{\mathrm{d}}-q$ being the angular position error.

The tendon Jacobian matrix $\boldsymbol{P}(q)$ relates joint and piston velocity by [20], [21]

$$
\dot{\boldsymbol{x}}_{\mathrm{p}}=\boldsymbol{P}(q)^{T} \dot{q} .
$$


The relation between tendon force $\boldsymbol{F}_{\mathrm{t}}$ and torque $\tau$ can then be written as

$$
\tau=\boldsymbol{P}(q) \boldsymbol{F}_{\mathrm{t}} .
$$

For the system in Fig. 2 the Jacobian takes the form

$$
\boldsymbol{P}(q)=\left(\begin{array}{ll}
-1 & 1
\end{array}\right) r,
$$

having full row rank. Then, given $\tau$, (26) has an infinite number of solutions $\boldsymbol{F}_{\mathrm{t}}$. Following [22], the entire set of solutions is represented by

$$
\boldsymbol{F}_{\mathrm{t}}=\boldsymbol{P}^{\dagger} \tau+\left(\boldsymbol{E}-\boldsymbol{P}^{\dagger} \boldsymbol{P}\right) \boldsymbol{f}=\boldsymbol{P}^{\dagger} \tau+\boldsymbol{F}_{\mathrm{P}}
$$

where $\boldsymbol{P}^{\dagger}=\boldsymbol{P}^{T}\left(\boldsymbol{P} \boldsymbol{P}^{T}\right)^{-1}=\frac{1}{2 r}\left(\begin{array}{ll}-1 & 1\end{array}\right)^{T}$ is the right inverse of $\boldsymbol{P}, \boldsymbol{E}$ is the identity matrix, and $\boldsymbol{f}$ an arbitrary vector. Inserting (28) into (26) confirms that $\boldsymbol{P}^{\dagger} \tau$ is one solution and $\boldsymbol{P F}_{\mathrm{P}}=\mathbf{0}$, i.e. $\boldsymbol{F}_{\mathrm{P}}$ does not affect $\tau$. In our case, the force vector $\boldsymbol{F}_{\mathrm{P}}$ takes the form

$$
\boldsymbol{F}_{\mathrm{p}}=\left(\boldsymbol{E}-\boldsymbol{P}^{\dagger} \boldsymbol{P}\right) \boldsymbol{f}=\left(\begin{array}{cc}
0.5 & 0.5 \\
0.5 & 0.5
\end{array}\right) \boldsymbol{f},
$$

where $\left(\boldsymbol{E}-\boldsymbol{P}^{\dagger} \boldsymbol{P}\right)$ has identical rows leading to identical components of $\boldsymbol{F}_{\mathrm{p}}$, which then does not affect $\tau$. Therefore, $\boldsymbol{F}_{\mathrm{p}}$ can be interpreted as the pretension force vector required to avoid slacking of the tendons. The desired force vector that is fed to the underlying force controller is given by

$$
\boldsymbol{F}_{\mathrm{d}}=\boldsymbol{P}^{\dagger} \tau_{\mathrm{d}}+\boldsymbol{F}_{\mathrm{P}}
$$

An alternative approach to the adjustment of $\boldsymbol{F}_{\mathrm{P}}$ can be found in [23]. The joint angle $q$ can either be measured directly on the joint shaft or obtained from the piston positions together with the tendon Jacobian. Since in our case $\boldsymbol{P}$ is constant $q$ becomes

$$
q=\boldsymbol{P}^{\dagger^{T}} \boldsymbol{x}
$$

\section{SIMULATION RESULTS}

The developed algorithms were first elaborated in simulation before their experimental realization. First, the inner force control loop is discussed. Thereafter, the performance of the joint impedance control on top of the force controller is elaborated. All results were obtained with Matlab/Simulink, where a fixed step Runge-Kutta solver at sample time $t_{s}=10^{-5} \mathrm{~s}$ was used. The sliding mode controllers were updated with a sampling time of $10^{-4} \mathrm{~s}$ in order to demonstrate the realtime applicability of the approach. Simulated models were numerically validated via energy and mass equivalences.

In [17] general adjustment rules for the magnitude of $\Gamma$ were described while the parameter $\kappa$ was tuned experimentally. These parameters already provided promising results for sinusoidal command inputs in first simulations. However, in our setup, the force control loop is the inner loop of a cascaded control scheme, requiring good tracking for arbitrary forms of the desired force (including steps). For further improving tracking performance, both force controller gains $\kappa$ and $\Gamma$ were adjusted based on minimizing the cost function $J=\sum_{k=0}^{N}\left(F_{\mathrm{d}, k}-F_{\mathrm{a}, k}\right)^{2}$ using a particle swarm algorithm within the simulation [24]. The Kalman filter gains of the 2nd order spool position observer were tuned manually until the error between simulated and estimated states was minimal and could not be improved anymore.

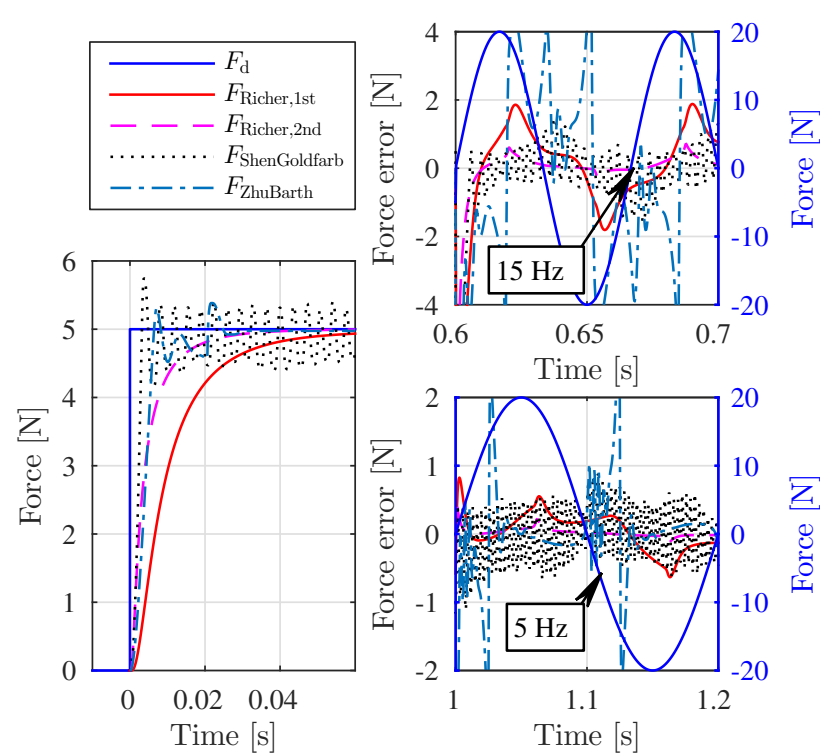

Fig. 4. Simulation: Force tracking results against a linear spring damper element $k=2000 \mathrm{~N} / \mathrm{m}, d=50 \mathrm{Ns} / \mathrm{m}$ for different $F_{\mathrm{d}}$ signals comparing different controllers from literature

TABLE II

ERRORS OF SINUSOIDAL FORCE TRACKING (SEE FIG. 4)

\begin{tabular}{c|c|c} 
& $|\bar{e}|[\mathrm{N}]-5 \mathrm{~Hz}$ & $|\bar{e}|[\mathrm{N}]-15 \mathrm{~Hz}$ \\
\hline Richer,1st & 0.2355 & 1.089 \\
Richer,2nd & 0.0423 & 0.3178 \\
ShenGoldfarb & 0.3465 & 0.7174 \\
ZhuBarth & 0.4073 & 2.4113 \\
\hline
\end{tabular}

\section{A. Pneumatic linear force control}

Figure 4 depicts the simulative force control results for the the 1st- and 2nd-order sliding mode controller by Richer et al. [17]. They are compared to the sliding mode force and stiffness controller from [10] and to the sliding mode pressure controller from [9], being the inner cascade of a cylinder level impedance controller from literature, see Tab. I. The stiffness in [10] was set to $800 \mathrm{~N} / \mathrm{m}$ to get rid of the additional degree of freedom in the force/stiffness controller. The pressure controllers from [9] are not used simultaneously, but one of the controllers is set to $P_{\text {atm }}$ while the other one tracks the required pressure to get the desired force $F_{\mathrm{d}}$. In this simulative experiment the cylinder (using the four controllers mentioned above) moves against a linear spring-damper system with stiffness $k=2000 \mathrm{~N} / \mathrm{m}$ and damping $d=50 \mathrm{Ns} / \mathrm{m}$.

Figure 4 (left) shows a force step of $5 \mathrm{~N}$, applied to the four controllers. The 1st and 2nd order force controllers by Richer et al. provide a clear asymptotic response with a response time of 0.025 and $0.01 \mathrm{~s}$. The controller by Zhu et al. reacts faster, but suffers on indistinct oscillations leading to a response time of $0.006 \mathrm{~s}$. The controller by Shen et al. is the fasted of the tested schemes but leads to high chattering. Table II shows the errors of the four controllers for $5 \mathrm{~Hz}$ and $15 \mathrm{~Hz}$ force tracking of Fig. 4 (right). In summary, the controllers by Richer et al. provide the lowest jerk and a response which is similar to a first order system.

Furthermore, an evaluation of the step time for these two controllers was carried out under ideal conditions (no sensor noise). It is important to note that the 2 nd-order sliding mode controller requires a sample time of at least $2 \times 10^{-4}$ s for operation. Otherwise, a chattering in force tracking was observed. The 1st-order sliding mode controller was less demanding in our simulations and required only $t_{\mathrm{s}}=10^{-3} \mathrm{~s}$, which 


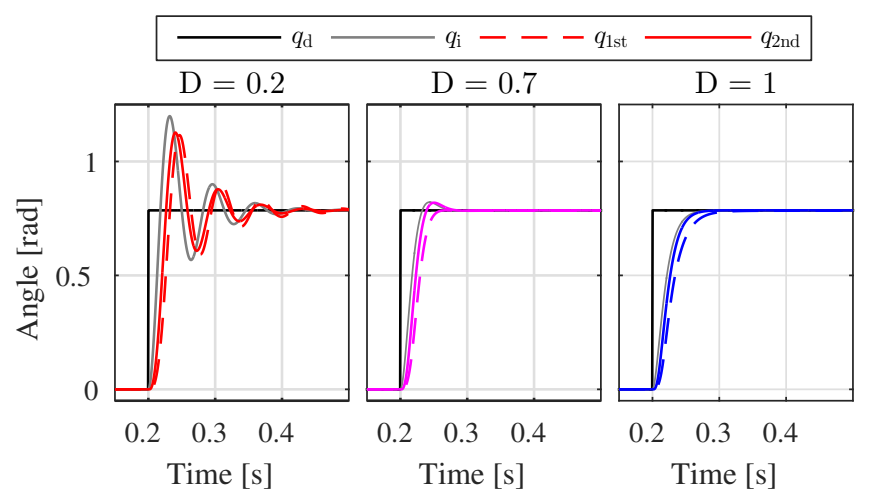

Fig. 5. Simulation: Step responses of antagonistic impedance control for different damping ratios

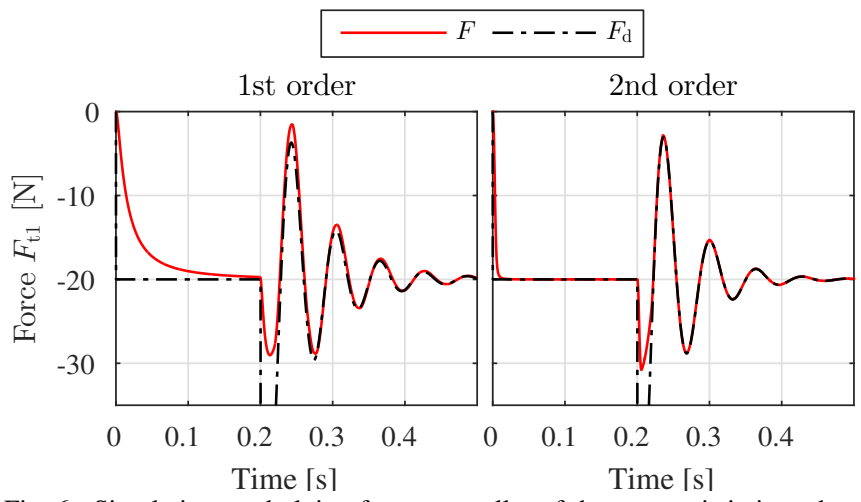

Fig. 6. Simulation: underlying force controller of the antagonistic impedance control from Fig. 5 with $D=0.2$

indicates that a larger stability margin was inherently provided in contrast to the 2nd-order type. However, for real-world disturbances, higher sampling rates are still required. These numerical results showed that both chosen force controllers by [17] have suitable performance. A slightly better time behavior of the 2nd-order could be shown compared to the 1st-order controller. The demanding sampling rates of the 2nd-order controller makes it, however, more reasonable to finally select the 1st-order type controller for the subsequent experimental analysis.

\section{B. Antagonistic impedance control}

The antagonistic structure from Fig. 2 together with the antagonistic impedance control from Fig. 3 is analyzed in this subsection. Fig. 5 shows the step response of the antagonistic impedance controlled system for a step change in $q_{\mathrm{d}}$ for three different damping ratios $D=0.2, D=0.7$ and $D=1$ with the 1st- and 2nd-order sliding mode force controllers. For validation purposes the system response is compared to an ideal impedance behavior $q_{\mathrm{i}}$ (gray line in plot), which is characterized by the following transfer function

$$
G(s)=\frac{\frac{k_{\text {imp }}}{\left(J+2 r^{2} M_{\mathrm{p}}\right)}}{s^{2}+2 D \sqrt{\frac{k_{\text {imp }}}{\left(J+2 r^{2} M_{\mathrm{p}}\right)}} s+\frac{k_{\text {imp }}}{\left(J+2 r^{2} M_{\mathrm{p}}\right)}} .
$$

The results show that the system resembles the behavior of (32) according to desired linear theory quite well. Minor differences can still be observed between 1st- and 2nd-order sliding mode controllers, which can be explained by the observations from Fig. 4.

The underlying force controller of the upper cylinder at $D=0.2$ is depicted in Fig. 6, again for both sliding mode controllers. In this application the better force-tracking performance of the 2nd-order controller is apparent in terms of lower response times and less overshoots. A large negative peak of $F_{\mathrm{d}}$ can be observed, which occurs when choosing a large $k_{\text {imp }}$. The output force $F_{\mathrm{a}}$ is not able to follow this value due to limited supply pressure.

\section{EXPERIMENTS}

An antagonistic joint setup was designed for experimentally validating our results, see Fig. 7.

\section{A. Hardware setup}

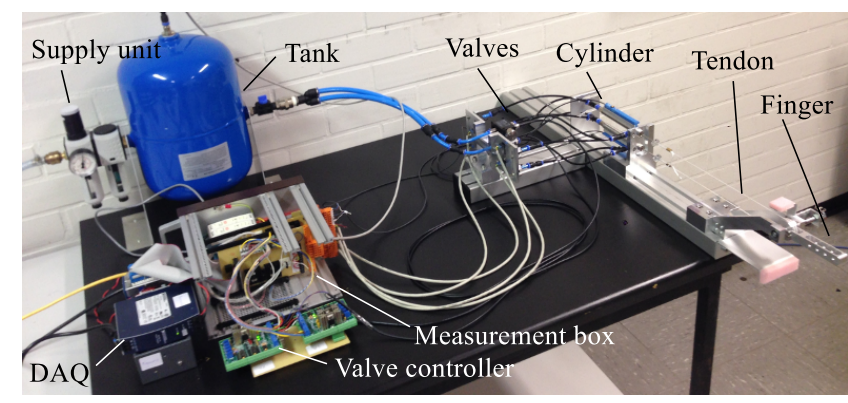

Fig. 7. Setup of pneumatic antagonistically driven robot joint

Special care in the design was taken on low-friction components. Two pneumatic low-friction cylinders Airpot Airpel E9 D 3.0 NM were chosen as basic actuator units together with contactless, high-accuracy position sensing $(0.1 \mathrm{~mm})$ via the SICK MPS-096TSTU0 magnetic position sensor. Two proportional valves LS-V05s by Enfield Technologies were chosen due to their high flow rate of $3.5 \mathrm{~g} / \mathrm{s}$ and bandwidth of $109 \mathrm{~Hz}$. For absolute pressure measurements, the 142 PC100A-PCB by First Sensor was chosen due to its fast response time of $0.1 \mathrm{~ms}$ and high accuracy of $0.1 \%$ FS. Data acquisition was done, using the National Instruments EtherCat Chassis NI9144 with analog in-/output modules NI9205 and NI9264. The control algorithms were executed on Matlab/Simulink using a realtime Linux Kernel.

\section{B. Model identification}

Since the parameters of cylinder and thermodynamic properties are known by design, the only left unknowns are the valve parameters. Two experiments were done to identify the discharge coefficient $c_{\mathrm{f}}$ and the orifice area function $A\left(x_{\mathrm{s}}\right)$. Up- and downstream measurements were performed and steady state mass flows $\dot{m}$ were measured using the mass flow gauge Profimess GR-02.1.2.1.1.0.0.L.D5.

The discharge coefficient $c_{\mathrm{f}}$ was identified under maximum valve voltage to enable a consideration of an orifice $A_{\max }$, known from the valve specification. Different up- and downstream pressures were applied to the valve. Pressure and mass flow measurements were applied to (3) and (4) in a leastsquares sense to then obtain $c_{\mathrm{f}}$. The identification of $A\left(x_{\mathrm{s}}\right)$ was done by setting different up- and downstream pressures to the valves for various positive and negative valve signals $u$. From mass flow and pressure measurements, a specific area can be calculated by (3) and (4) and $c_{\mathrm{f}}$. B-splines were fit through the voltage and area estimations. The parameter $c_{\mathrm{f}}$ was identified to be 0.38 . The results of the orifice area identification are depicted in Fig. 8. 


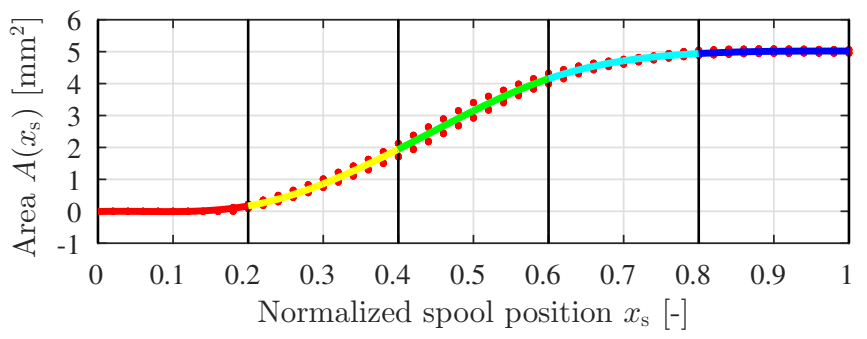

Fig. 8. Experiment: Identified orifice area of the valve using B-splines

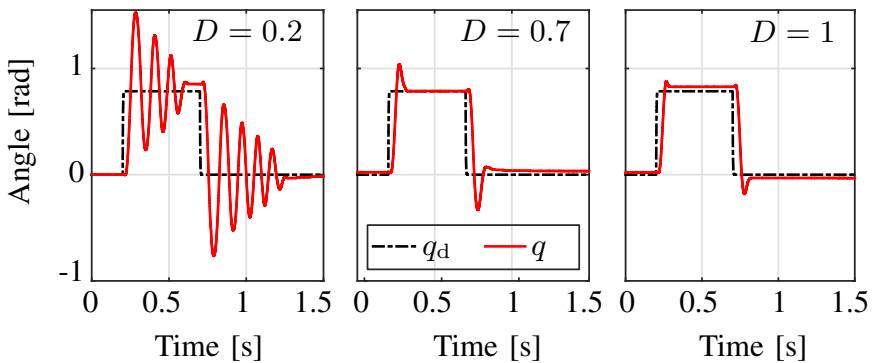

Fig. 9. Experiment: System response of antagonistic impedance control for different damping ratios

\section{Control algorithms}

The impedance control was implemented on top of the 1storder sliding mode control using a step time of $t_{\mathrm{s}}=4 \times 10^{-4}$ s. Most parameters for the model/controller were obtained from technical manuals of the components, see Sec. VI-A. Mechanical quantities of the joint link are $r=0.018 \mathrm{~m}$, $J=1.51 \times 10^{-4} \mathrm{kgm}^{2}, l_{\mathrm{CM}}=0.025 \mathrm{~m}, M_{j}=0.079 \mathrm{~kg}$. The valve rise time is assumed to be $\tau=0.0015 \mathrm{~s}$. The force controller parameters $\kappa=4.78$ and $\Gamma=4.347 \times 10^{3}$ $\mathrm{s}^{2} \mathrm{~kg}^{-1} \mathrm{~m}^{-1}$ were tuned manually based on optimized parameters from simulation, see Sec. V. In contrast to the previous simulation, position measurements $x_{\mathrm{p}}$ and desired forces $F_{\mathrm{d}}$ were filtered by a first order digital filter $\left(T_{\text {filt }, \mathrm{x}}=0.0013 \mathrm{~s}\right.$, $T_{\text {filt,F }}=0.0029 \mathrm{~s}$ ) to achieve an improved system performance (less chattering). Alternatively, we implemented numerical differentiation using a DT1 filtering, where similar, however, no improved performance could be achieved. In comparison, [17] used 2nd-order filter.

Regarding the performance of the impedance controller, a maximum stiffness of $1.20 \mathrm{Nm} / \mathrm{rad}$ at $D=0.7$ could be achieved until oscillations occur. A linear relation between torque and angular displacement yields up to the maximum achievable tendon force, depending on the supply pressure. However, above this value the system still reacts compliantly due to the compressibility of air (see Fig. 13). In order to obtain a linear force/displacement relation within a joint angle of $\pm 45^{\circ}$, maximum and minimum tendon forces were designed to be $-20 \mathrm{~N}$ and $-5 \mathrm{~N}$ for both tendons. Consequently, a tendon pretension of $F_{\mathrm{p}}=-12.5 \mathrm{~N}$ and a stiffness of $k_{\mathrm{imp}}=0.3438$ $\mathrm{Nm} / \mathrm{rad}$ was chosen. Adapting $F_{\mathrm{p}}$ in order to minimize the overall tendon forces was not implemented yet.

Please note that the lower cylinder slightly lost its low friction properties in the course of our experiments which decreased the position tracking in Fig. 12.

Figure 9 depicts a system response test, which replicates the simulation experiment from Fig. 5. The comparison reveals a similar system behavior according to linear theory. The experimental setup reflects the expectation for the chosen damping ratios. However, in comparison to simulation, the experimental system produces slightly larger overshoots. Due

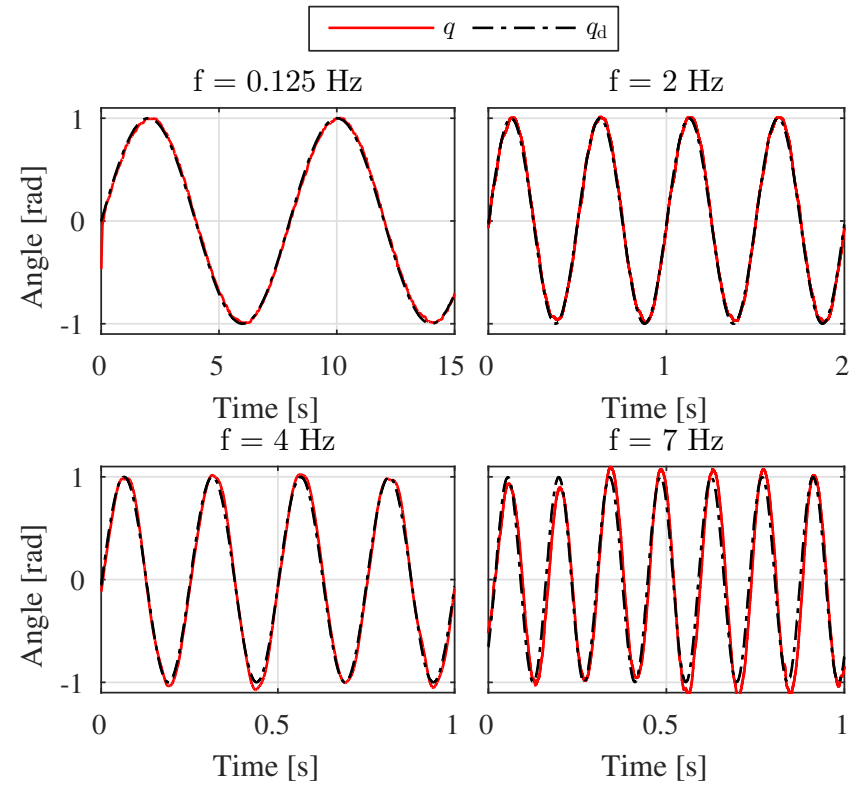

Fig. 10. Experiment: position tracking of antagonistic impedance control

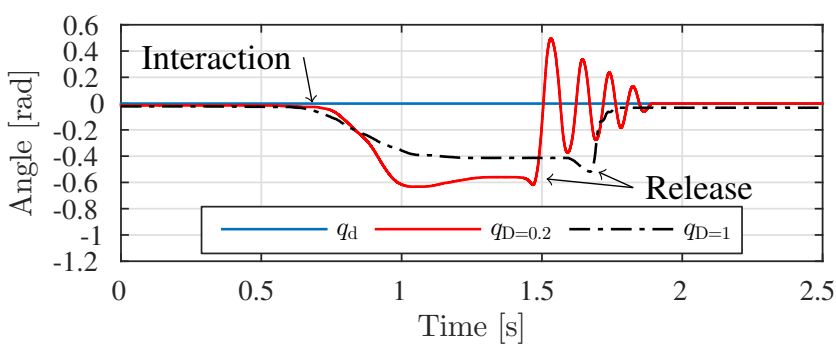

Fig. 11. Experiment: Human interaction by application of an external force and system response for $D=0.2$

to a lower supply pressure of 3.5 bar the required forces, which are needed for deceleration, are not achieved, leading to the observed overshoots.

Figure 10 depicts tracking performance for different sinusoidal signals. Additionally, the feed-forward term $\tau_{\mathrm{ff}}$ (see (21)) was added to the control law in order to compensate inertia influences. The desired joint angle $q_{\mathrm{d}}$ at $0.125,2,4$, and $7 \mathrm{~Hz}$ is achieved correctly for all frequencies. At $7 \mathrm{~Hz}$ some noticeable deviation $q$ can be observed. The mean absolute errors are $\overline{|e|}_{0.125 \mathrm{~Hz}}=1.2^{\circ} \approx 0.021 \mathrm{rad}, \overline{|e|}_{2 \mathrm{~Hz}}=2.4^{\circ} \approx 0.042 \mathrm{rad}$, $\overline{|e|}_{4 \mathrm{~Hz}}=1.6^{\circ} \approx 0.028 \mathrm{rad}$ and $\overline{|e|}_{7 \mathrm{~Hz}}=7.6^{\circ} \approx 0.133 \mathrm{rad}$.

Figure 11 shows the reaction of the system for two different damping ratios during interaction with a human hand. The desired angle is chosen to be $q_{\mathrm{d}}=0 \mathrm{rad}$. Starting at $t=0.6 \mathrm{~s}$ one can observe a deflection of the system, which is caused by the compliance of the system. After the system is released it responses with its particular viscoelastic behavior.

Figure 12 elaborates sudden contacts of the system during tracking operation. The contact is realized by an obstacle, which is moved under the finger. The experiments show that the system remains stable also in case of rigid contact and is able to proceed with the tracking after $q_{\mathrm{d}}$ moves out of the obstacle range again. This behavior is also reflected by the force control behavior. When motion is inhibited by the obstacle, the impedance control law increases the force to the position error accordingly. The force controller is able to track the desired input force from the impedance controller. Furthermore, symmetric distribution of actuator forces can be noted as described by (30). 


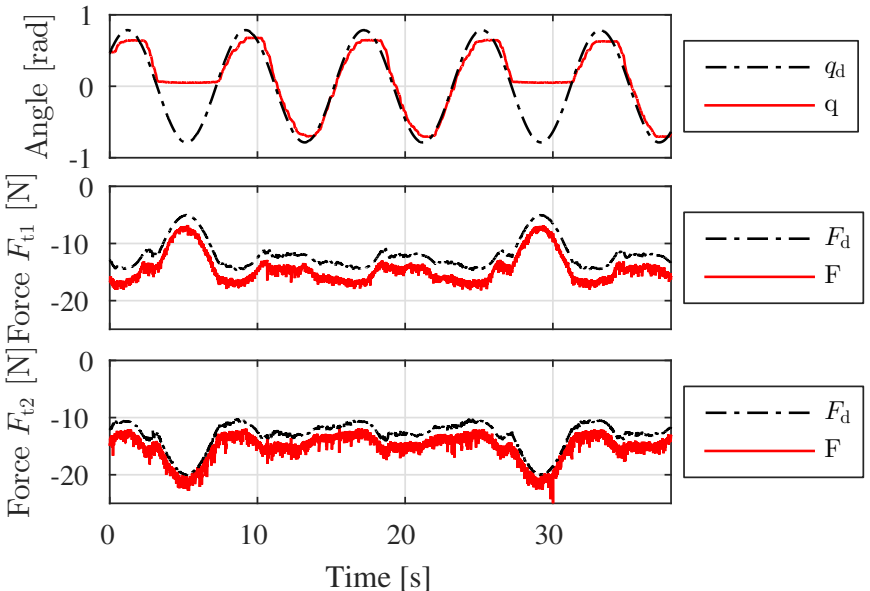

Fig. 12. Experiment: System response in case of obstruction by an obstacle

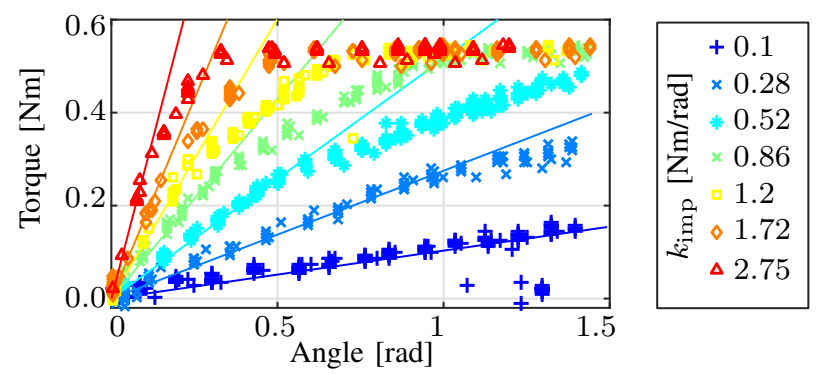

Fig. 13. Experiment: Static torque-deflection characteristics of the impedance controlled finger

An investigation of the static stiffness characteristics is shown in Fig. 13. An experiment was carried out at $q_{\mathrm{d}}=0$ $\mathrm{rad}$. From this set point the link is deflected in small angular steps up to $\pi / 2$ for stiffness values from 0.1 to $2.75 \mathrm{Nm} / \mathrm{rad}$. The markers in Fig. 13 represent force measurements for specific deflections. The solid lines show the ideally adjusted stiffness during the experiment. It can be observed that the expected torques are achieved correctly for smaller angular displacements. For increasing stiffnesses earlier detachment from the ideal stiffness characteristic line can be observed. This detachment is caused by the particular choice of $\boldsymbol{F}_{\mathrm{p}}$ in (30) in combination with a linear distribution of tension forces, which increases one tendon force while decreasing the other. When the lower tendon force reaches a predefined lower boundary, it saturates to prevent slacking. Furthermore, a maximum torque of about $0.55 \mathrm{Nm}$ can be observed, which follows from supply pressure $P_{\text {sup }}$ and cylinder piston areas $A_{1}$ and $A_{2}$. Finally, it can be stated that all defined stiffnesses are achieved correctly for angles lower than $0.1 \mathrm{rad}$.

\section{CONCLUSION}

In this paper, a novel joint torque-based impedance controller for pneumatically actuated, antagonistically driven flexible joints was proposed and analyzed. The developed system achieves all essential soft-robotics and motion capabilities so that it could be applied to similar tasks as joint torque controlled lightweight robots with high gearing and high quality DC motors, however at presumably much lower costs. Compliant system reactions and stable contact behavior could be demonstrated with very good performance compared to the state of the art. Also, fast angular position tracking at $7 \mathrm{~Hz}$ was achieved. The maximum stiffness of $2.75 \mathrm{Nm} / \mathrm{rad}$ is about 5.5 times higher than a human MCP joint [25]. Next steps will be the extension to multi-joint structures for robotic and prosthetic hands. For this, a reduction of the form factor of our design becomes crucial.

\section{REFERENCES}

[1] D. Whitney, "Quasi-static assembly of compliantly supported rigid parts," ASME J. of Dynamic Systems, Measurement, and Control, vol. 99, pp. $65-77,1982$.

[2] J. Craig and M. Raibert, "A systematic method for hybrid position/force control of a manipulator," IEEE Computer Software Applications Conf., pp. 446-451, 1979.

[3] R. Paul and B. Shimano, "Compliance and control," in Joint Automatic Control Conf. (JACC1976), San Francisco, USA, pp. 694-699, 1976.

[4] J. Salisbury, "Active stiffness control of a manipulator in cartesian coordinates," in Decision and Control including the Symposium on Adaptive Processes, 1980 19th IEEE Conference on, pp. 95-100, Dec 1980.

[5] N. Hogan, "Impedance control: An approach to manipulation, part I theory," ASME Journal of Dynamic Systems, Measurement, and Control, vol. 107, pp. 1-7, 1985.

[6] C. Ott, Cartesian Impedance Control of Redundant and Flexible-Joint Robots. Springer Publishing Company, Incorporated, 2008.

[7] B. Taheri, D. Case, and E. Richer, "Force and stiffness backsteppingsliding mode controller for pneumatic cylinders," IEEE/ASME Transactions on Mechatronics, pp. 1-11, 2013.

[8] E. Richer and Y. Hurmuzlu, "A high performance pneumatic force actuator system: Part inonlinear mathematical model," Journal of dynamic systems, measurement, and control, vol. 122, no. 3, pp. 416-425, 2000.

[9] Y. Zhu and E. Barth, "Impedance control of a pneumatic actuator for contact tasks," in Robotics and Automation, 2005. ICRA 2005. Proceedings of the 2005 IEEE International Conference on, pp. 987992, April 2005.

[10] X. Shen and M. Goldfarb, "Simultaneous force and stiffness control of a pneumatic actuator," Journal of Dynamic Systems, Measurement, and Control, vol. 129, no. 4, pp. 425-434, 2007.

[11] N. H. Arbab and F. Najafi, "Stability and performance of pneumatic actuators in impedance control," Proceedings of the Institution of Mechanical Engineers, Part I: Journal of Systems and Control Engineering, vol. 228 , no. 7, pp. 476-485, 2014.

[12] T. Noritsugu and T. Tanaka, "Application of rubber artificial muscle manipulator as a rehabilitation robot," Mechatronics, IEEE/ASME Transactions on, vol. 2, pp. 259-267, Dec 1997.

[13] I. Sardellitti, J. Park, D. Shin, and O. Khatib, "Air muscle controller design in the distributed macro-mini (dm2) actuation approach," in Intelligent Robots and Systems, 2007. IROS 2007. IEEE/RSJ International Conference on, pp. 1822-1827, Oct 2007.

[14] I. Sardellitti, G. Palli, N. Tsagarakis, and D. Caldwell, "Antagonistically actuated compliant joint: Torque and stiffness control," in Intelligent Robots and Systems (IROS), 2010 IEEE/RSJ International Conference on, pp. 1909-1914, Oct 2010.

[15] B. Ugurlu, P. Forni, C. Doppmann, and M. Jun, "Torque and variable stiffness control for antagonistically driven pneumatic muscle actuators via a stable force feedback controller," in 2015 IEEE/RSJ International Conference on Intelligent Robots and Systems (IROS), 2015.

[16] B. Vanderborght, A. Albu-Schäffer, A. Bicchi, E. Burdet, D. G. Caldwell, R. Carloni, M. Catalano, O. Eiberger, W. Friedl, G. Ganesh, et al., "Variable impedance actuators: A review," Robotics and Autonomous Systems, vol. 61, no. 12, pp. 1601-1614, 2013.

[17] E. Richer and Y. Hurmuzlu, "A high performance pneumatic force actuator system: part iinonlinear controller design," Journal of dynamic systems, measurement, and control, vol. 122, no. 3, pp. 426-434, 2000.

[18] P. Beater, Pneumatic Drives. Berlin, Heidelberg: Springer Berlin Heidelberg, 2007.

[19] S. Julier and J. Uhlmann, "Unscented filtering and nonlinear estimation," Proceedings of the IEEE, vol. 92, pp. 401-422, Mar 2004.

[20] R. M. Murray, A Mathematical Introduction to Robotic Manipulation. CRC press, 1994.

[21] T. Wimböck, Controllers for Compliant Two-Handed Dexterous Manipulation, vol. 17 of Modellierung und Regelung komplexer dynamischer Systeme. Aachen: Shaker Verlag, 2013.

[22] M. James, "The generalised inverse," The Mathematical Gazette, pp. 109-114, June 1978.

[23] G. Palli, G. Borghesan, and C. Melchiorri, "Modeling, identification, and control of tendon-based actuation systems," Robotics, IEEE Transactions on, vol. 28, pp. 277-290, April 2012.

[24] B. Birge, "Psot - a particle swarm optimization toolbox for use with matlab," in Swarm Intelligence Symposium, 2003. SIS '03. Proceedings of the 2003 IEEE, pp. 182-186, April 2003.

[25] Z. Xu, E. Todorov, B. Dellon, and Y. Matsuoka, "Design and analysis of an artificial finger joint for anthropomorphic robotic hands," in Robotics and Automation (ICRA), 2011 IEEE International Conference on, pp. 5096-5102, IEEE, 2011. 